\title{
Diagnosis and management of hereditary haemochromatosis
}

Citation for published version (APA):

van Bokhoven, M. A., van Deursen, C. T. B. M., \& Swinkels, D. W. (2011). Diagnosis and management of hereditary haemochromatosis. BMJ, 342, 218-223. https://doi.org/10.1136/bmj.c7251

Document status and date:

Published: 19/01/2011

DOI:

10.1136/bmj.c7251

Document Version:

Publisher's PDF, also known as Version of record

Document license:

Taverne

Please check the document version of this publication:

- A submitted manuscript is the version of the article upon submission and before peer-review. There can be important differences between the submitted version and the official published version of record.

People interested in the research are advised to contact the author for the final version of the publication, or visit the DOI to the publisher's website.

- The final author version and the galley proof are versions of the publication after peer review.

- The final published version features the final layout of the paper including the volume, issue and page numbers.

Link to publication

\footnotetext{
General rights rights.

- You may freely distribute the URL identifying the publication in the public portal. please follow below link for the End User Agreement:

www.umlib.nl/taverne-license

Take down policy

If you believe that this document breaches copyright please contact us at:

repository@maastrichtuniversity.nl

providing details and we will investigate your claim.
}

Copyright and moral rights for the publications made accessible in the public portal are retained by the authors and/or other copyright owners and it is a condition of accessing publications that users recognise and abide by the legal requirements associated with these

- Users may download and print one copy of any publication from the public portal for the purpose of private study or research.

- You may not further distribute the material or use it for any profit-making activity or commercial gain

If the publication is distributed under the terms of Article $25 \mathrm{fa}$ of the Dutch Copyright Act, indicated by the "Taverne" license above, 
Intended for healthcare professionals

thebmj

Clinical Review

\section{Diagnosis and management of hereditary haemochromatosis}

BMJ 2011; 342 doi: https://doi.org/10.1136/bmj.c7251 (Published 19 January 2011) Cite this as: BMJ 2011;342:c7251

M A van Bokhoven, general practitioner and assistant professor in general practice ${ }^{1}$, C Th B M van Deursen, consultant internal medicine 2 , D W Swinkels, professor of clinical chemistry 3

${ }^{1}$ Maastricht University, School for Public Health and Primary Care (CAPHRI), Department of General Practice, 6200 MD Maastricht, Netherlands

2 Department of Internal Medicine and Gastroenterology, Atrium Medisch Centrum Parkstad, 6401 CX Heerlen, Netherlands

${ }^{3}$ Department of Laboratory Medicine, Radboud University Nijmegen Medical Centre, 6500 HB Nijmegen, Netherlands

Correspondence to: M A van Bokhoven loes.vanbokhoven@hag.unimaas.nl

- Accepted 6 December 2010

\section{Summary points}

Hereditary haemochromatosis is an autosomal recessive disorder with a genetic prevalence of $0.4 \%$ in northern Europeans but a much lower clinical penetrance

Those affected are at increased risk of cirrhosis of the liver and hepatocellular carcinoma

Symptoms are often non-specific at presentation and include fatigue and arthropathy

If transferrin saturation and serum ferritin are raised, test for $\mathrm{C} 282 \mathrm{Y}$ mutation of the HFE gene

First degree relatives of patients with clinically overt haemochromatosis can be screened for C282Y and H63D polymorphisms

Regular phlebotomy is the main treatment, although newly developed therapeutic approaches show promise

Hereditary haemochromatosis is an autosomal recessive genetic disease in which increased intestinal absorption of iron causes accumulation in tissues, primarily the liver, sometimes leading to organ damage. Liver deposits may result in cirrhosis and even death. A systematic review has shown that about $0.4 \%$ of people of northern European descent have the genetic mutation that increases the risk of developing haemochromatosis, 1 but the clinical penetrance of the mutation is much lower than the genetic prevalence. Symptoms and signs are initially non-specific, so the disease is often diagnosed at a late stage when substantial organ damage has already occurred. The challenge is to avoid both overdiagnosis and underdiagnosis. Since the discovery of the genetic mutation, new knowledge has come to light on the pathophysiology and course of the disease. This has led to new recommendations on diagnosis and treatment. In addition, new treatments are under evaluation. We review 
evidence from experimental and observational studies, systematic reviews, and guidelines to summarise for the general reader the clinical presentation, diagnosis, including early screening options, and management of hereditary haemochromatosis.

\section{Sources and selection criteria}

Initially, we made an extensive search of Medline, Embase, and the Cochrane Library for papers published until December 2009 using both MESH headings and free text related to hereditary haemochromatosis. In addition, we retrieved national and international guidelines and checked the references of the papers that we obtained. The overall methodological quality of the papers was low. Although many reviews were available, they were mostly narrative. The more recent literature seems to be of better quality.

\section{What is hereditary haemochromatosis?}

"Hereditary haemochromatosis" is a heterogeneous group of disorders (box) related to deficiency of the iron regulatory hormone hepcidin (fig $1 \Downarrow$ ).2 Organs that may be affected by iron deposits include the liver, pancreas, joints, heart, skin, and gonads. Hereditary haemochromatosis must be distinguished from secondary forms of iron overload, such as those caused by repeated red blood cell transfusions or anaemia owing to ineffective erythropoiesis (fig $2 \Downarrow$ ). Although all lead to raised serum iron parameters, they are treated differently. Recent consensus from the European Association for the Study of the Liver (EASL) defines hereditary haemochromatosis as "C282Y homozygosity and increased body iron stores with or without clinical symptoms." 1

\section{Differential diagnosis of hereditary haemochromatosis}

\section{Hereditary haemochromatosis}

HFE associated hereditary haemochromatosis (type 1)

C282Y homozygosity

C282Y/H63D compound heterozygosity

Other HFE gene defects

\section{Non-HFE associated hereditary haemochromatosis}

Haemojuvelin gene defect

Hepcidin gene defect

Transferrin receptor 2 gene defect

Ferroportin gene defect

\section{Other hereditary forms of haemochromatosis}

Hereditary $\mathrm{H}$ ferritin cataract syndrome

Haem oxygenase deficiency 
Neonatal iron overload

Aceruloplasminaemia

Congenital atransferrinaemia or hypotransferrinaemia

Divalent metal transporter 1 gene defect

\section{Secondary iron overload}

Iron loading anaemias

Ineffective erythropoiesis

Thalassaemic syndromes

Sideroblastic anaemia

Myelodysplastic syndrome

Congenital dyserythropoietic anaemia

Parenteral iron overload (including multiple blood transfusions)

\section{Other diagnoses}

Metabolic syndrome

Obesity

Hypertension

Insulin resistance

Drug toxicity

Chronic haemodialysis

Chronic liver disease

Hepatitis

Alcohol misuse

Non-alcoholic steatohepatitis

Porphyria cutanea tarda

Liver cirrhosis

Iron overload in sub-Saharan Africa 


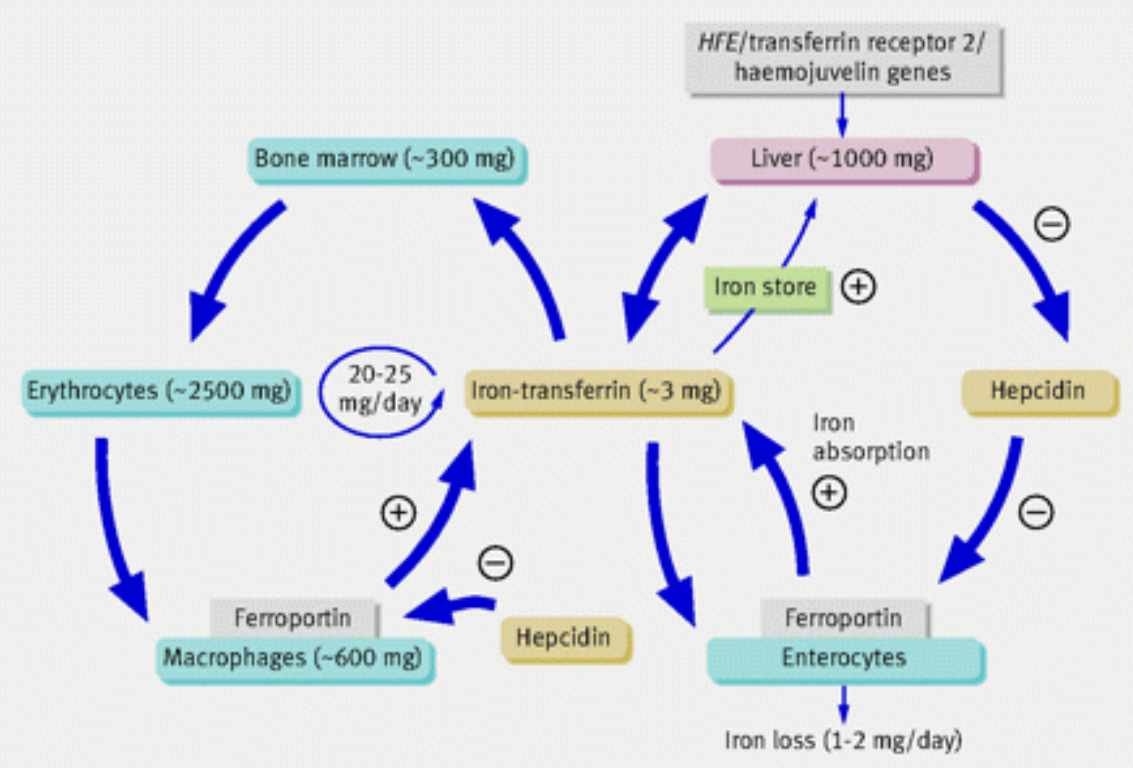

Fig 1 Role of hepcidin in the pathophysiology of hereditary haemochromatosis. The largest flux of iron involves the recycling of iron from senescent erythrocytes out of macrophages for incorporation into erythroid precursors (all values are approximate). Liver and reticuloendothelial macrophages function as major iron stores. Only 1-2 mg of iron is absorbed and lost every day. Importantly, the total amount of iron in the body can be regulated only by absorption, while iron loss occurs only passively from sloughing of skin and mucosal cells and from blood loss. Defects in genes encoding proteins that regulate synthesis of the iron regulatory hormone hepcidin in hepatocytes result in a decrease of serum hepcidin concentrations. Hepcidin controls the plasma iron concentration by inhibiting iron export by ferroportin from duodenal enterocytes and reticuloendothelial macrophages. A decrease in hepcidin production results in raised plasma iron values and accumulation of iron in the body

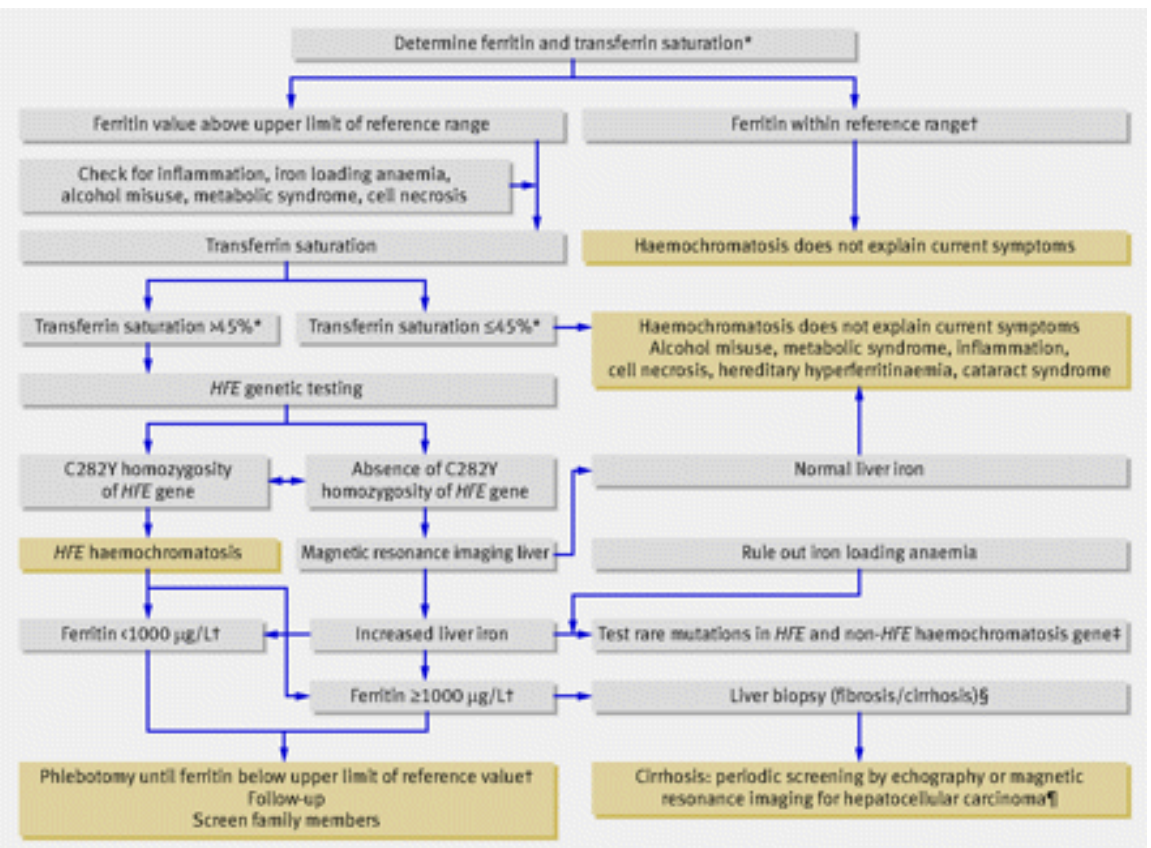

Fig 2 Diagnostic flowchart for patients with suspected haemochromatosis. *The reference range for transferrin saturation is $15-45 \%$. $†$ The ferritin range differs between laboratories and methodologies used. Usual upper reference values are about $300 \mu \mathrm{g} / \mathrm{L}$ and $200 \mu \mathrm{g} / \mathrm{L}$ for men and women, respectively. $\ddagger$ If rare HFE mutations are present the diagnosis is HFE haemochromatosis; if mutations in the genes for the transferrin receptor 2 , haemojuvelin, hepcidin, or ferroportin are detected the diagnosis is non-HFE haemochromatosis; in the presence of any of these mutations, treat patients the same as those with HFE haemochromatosis regarding phlebotomy, screening relatives, and periodic screening of the liver in those with liver cirrhosis. §Iron overload in the liver may also result from end stage cirrhosis; in exceptional 
cases, further diagnostic considerations then depend on cellular and nodular distributions of iron and associated findings such as fibrosis on liver biopsy. TIn the absence of cirrhosis, regular screening by echography or magnetic resonance imaging is not indicated

A meta-analysis of 2802 people of European ancestry who had clinical iron overload found that $81 \%$ were homozygous for the $\mathrm{C} 282 \mathrm{Y}$ mutation in the HFE gene on the short arm of chromosome 6. A smaller proportion (5\%) were compound heterozygous for the $\mathrm{C} 282 \mathrm{Y} / \mathrm{H} 63 \mathrm{D}$ mutations.1 Several other mutations in the HFE gene have been described, but these are rare. 3 Here, we focus on C282Y homozygous haemochromatosis with increased body iron stores, which we refer to as haemochromatosis.

A systematic review of longitudinal prognostic studies found that $38-76 \%$ of homozygous people develop raised iron parameters, such as ferritin and transferrin saturation in the blood (biochemical penetrance). 4 However, clinical penetrance is lower-2-38\% in men and 1-10\% in women.5 6 The lower clinical penetrance in women is thought to result from iron loss through menstrual bleeding and childbirth, although evidence is lacking. Genetic polymorphisms, antioxidant activity, inflammation, and environmental factors-such as alcohol misuse, steatosis, and coexisting viral infections-also seem to modify the risk of developing clinically overt disease.7 8

\section{What are the presenting symptoms and signs?}

Diabetes, bronzing of the skin, hepatomegaly, and arthropathy, especially of the second and third metacarpophalangeal joints, are typical presenting features. However, these are symptoms of advanced disease, and symptoms in early disease are non-specific. Case reports and observational studies have identified a wide range of other symptoms such as fatigue, arthropathy in other joints, non-specific abdominal problems, erectile dysfunction, and cardiac problems.910 All symptoms are thought to be caused by iron deposition in organs, although evidence on the relation between symptoms and the extent of iron overload is limited.1611 1213 No studies have looked at the predictive value of combinations of symptoms. Thus, it is difficult to identify patients with haemochromatosis from their symptoms and signs, especially for generalists, who usually see patients with early, non-specific symptoms and signs rather than advanced disease.

\section{How can haemochromatosis be distinguished from other diseases?}

To treat patients correctly, clinicians need to distinguish haemochromatosis from other diseases that result in iron overload, from diseases that lead to high serum ferritin without iron overload, and from diseases that present in a similar way, particularly with liver dysfunction. The box lists the differential diagnoses.

The first tests to do in patients with suspected iron overload are measurement of iron and transferrin (which enables transferrin saturation to be calculated) and serum ferritin (fig 2).159 14 HFE genetic testing is needed only in those with increased transferrin saturation and after exclusion of common causes of hyperferritinaemia: inflammation (check $\mathrm{C}$ reactive protein), chronic alcohol consumption, liver cell necrosis (alanine aminotransferase), metabolic syndrome (blood pressure, body mass index, triglycerides, and glucose), anaemia (haemoglobin, mean cellular volume, and ethnic background) as recommended by international guidelines (box). 1 If the patient is $\mathrm{C} 282 \mathrm{Y}$ homozygous the diagnosis of HFE haemochromatosis can be established. In the absence of these mutations, perform magnetic resonance imaging to assess liver iron stores.15 If liver iron is high and other diseases with liver iron loading, especially iron loading anaemias, have been excluded, perform molecular analysis for rare HFE mutations and mutations in the genes that encode haemojuvelin, hepcidin, transferrin receptor 2, and ferroportin, according to clinical, laboratory, and pathological features.16

People who present with symptoms of haemochromatosis and who are C282Y homozygous typically have higher than normal transferrin saturation and ferritin as a result of disrupted iron homeostasis. The concentration of 
serum ferritin depends on the amount of iron stored in the body. With high iron load ferritin is usually high, and this may correlate with the development of signs and symptoms of iron overload.12

\section{Transferrin saturation}

Transferrin saturation is the proportion of the iron transport protein transferrin that is saturated with iron; it is calculated as follows: ((serum iron $(\mu \mathrm{mol} / \mathrm{L}): 25) /$ transferrin $(\mathrm{g} / \mathrm{L})) \times 100 \%$. In haemochromatosis, transferrin saturation is generally increased throughout the day, and a non-fasting measurement will detect high values. Transferrin saturation is raised as a result of innately low hepcidin, which leads to increased iron uptake from the intestine and iron release by reticuloendothelial macrophages.17 Transferrin saturation can also be high in people with iron loading anaemias, those taking iron tablets or multivitamins containing iron, patients with hepatitis, and people who misuse alcohol.

The reference range for transferrin saturation is $15-45 \%$; expert consensus considers $45 \%$ to be the upper limit of normal in a non-fasting situation,19 although higher cut-off values are sometimes recommended for population screening programmes. 18

\section{Serum ferritin}

Serum ferritin is an indirect measure of body iron stores and is increased in patients with iron overload, viral infections, other inflammatory conditions, the metabolic syndrome, cancer, and chronic liver disease (for example, as a result of alcohol misuse); it is also raised in patients on dialysis and as a result of drug toxicity. Many immunochemical methods are available to measure serum ferritin. We recommend using local reference values because the inter-laboratory coefficient of variance of serum ferritin concentrations is high, 6-13\% (source: Foundation of quality control of medical laboratory diagnostics (SKML) data on interlaboratory variance of serum ferritin from about 270 Dutch laboratories in 2009). Upper reference values are about $300 \mu \mathrm{g} / \mathrm{L}$ and $200 \mu \mathrm{g} / \mathrm{L}$ for men and women, respectively.

\section{Genetic testing}

When symptoms and serum iron parameters suggest haemochromatosis genetic testing is indicated. A systematic review found sensitivity and specificity of C282Y homozygosity to be above $90 \%$ and almost $100 \%$, respectively, for the presence of an iron overload phenotype in white northern Europeans.19

A recent prospective population based cohort study showed that documented iron overload disease is rare among C282Y/H63D compound heterozygotes.20 An advantage of genetic testing in patients with signs of increased iron stores is the certainty of the diagnosis, and this has important implications for treatment and counselling of first degree relatives. If a symptomatic patient is a $\mathrm{C} 282 \mathrm{Y}$ homozygote, screening of first degree relatives for the presence of the genotype may be indicated.21

\section{Magnetic resonance imaging and liver biopsy}

If the diagnosis is still unsure after blood analysis and testing for the C282Y and H63D polymorphisms of the HFE gene, magnetic resonance imaging might be helpful. A reliable, quantitative imaging technique for the detection of iron in the liver is available.15 If the expertise or facilities to offer the technique is lacking, tissue from a liver biopsy may be analysed to look for iron deposits. If the concentration of iron deposits is below the cut-off value, haemochromatosis can be excluded, but if it is above, genetic testing for rare haemochromatosis mutations is indicated.9

\section{What is the prognosis for patients with haemochromatosis?}

A meta-analysis found that $\mathrm{C} 282 \mathrm{Y}$ homozygous patients with clinically ascertained haemochromatosis have an increased risk of developing liver disease (odds ratio 3.9, 99\% confidence interval 1.9 to 8.1) and hepatocellular carcinoma (11, 3.7 to 34$) .11$ A population screening survey of 65238 people showed that the absolute risk of liver damage is about $5 \%$ in homozygous men and less than $1 \%$ in women.22 Patients with either of these complications have a reduced life expectancy. However, observational studies of patients who received adequate 
and timely treatment, of people identified by population screening, and of previously undiagnosed family members of patients with haemochromatosis show that overall mortality is not higher than in the general population.5 232425

\section{Is screening indicated?}

\section{Population screening}

The relatively high prevalence of the C282Y homozygous genotype in European populations led several authors to recommend population screening.26 27 However, the low clinical penetrance means that many people would be incorrectly diagnosed with haemochromatosis when not clinically unwell, which could be harmful and could lead to problems with obtaining medical insurance. A systematic review therefore concluded that population screening is not recommended because the harms exceed the benefits. 28

\section{Screening those with haemochromatosis related diseases}

New EASL guidelines recommend considering genetic testing for patients with porphyria cutanea tarda, well defined chondrocalcinosis, hepatocellular carcinoma, late onset type 1 diabetes, and those presenting with a combination of unexplained chronic liver disease and raised transferrin saturation. Although the evidence is limited, these diseases are associated with a higher prevalence of C282Y homozygosity. 1

\section{Screening people with a positive family history}

Screening first degree relatives of patients diagnosed with haemochromatosis is another option. A modelling study showed that for patients with two or more children, the most cost effective approach is to test the patient's spouse first and test the children only if the spouse is heterozygous. For one child or siblings, direct testing for the mutation is the most cost effective strategy.21 The value of testing for the C282Y mutation is still unclear because of the unknown risk of developing biochemical or clinical signs of haemochromatosis even in homozygotes. This is even more the case when testing for $\mathrm{C} 282 \mathrm{Y} / \mathrm{H} 63 \mathrm{D}$ compound heterozygosity. This is because the chance of finding this genotype in relatives of a $\mathrm{C} 282 \mathrm{Y}$ homozygous proband is relatively high (the population frequency of the H63D mutation is $20 \%$ ); documented iron overload in people with this genotype is rare20; and disease penetrance in the absence of comorbid factors is low, as is shown in an observational study.29

\section{Patient's story}

The first symptom was painful swelling of my hand, for which I was referred to a rheumatologist. He suspected haemochromatosis because of my bronzed skin and ordered the relevant tests. In retrospect, this explains my "fatty liver" that had been diagnosed by a screening test at work. After the diagnosis I was treated with frequent phlebotomies, which made me so tired that I could no longer work full time. Currently, my worst problem is pain in my hips and finger. None of the available painkillers is effective. Furthermore, I have fatigue, which means that I have to plan my activities carefully. Thirdly, I have erectile dysfunction. Fortunately, my wife and I have found other ways to reach intimacy. My children and my sisters have been screened for the mutation and had their iron parameters measured. Luckily, none of them are affected. I used to undergo phlebotomies biweekly. However, since I have been given esomeprazol my iron parameters remain stable and I no longer need to be bled. I worry about symptoms that might arise in the future, such as problems with my heart.

However, an observational study of first degree relatives of C282Y homozygous patients found that haemochromatosis related symptoms are more common than in controls and that their level of iron overload may be predicted by disease severity in the index patient.25 30 Because the first symptoms develop during adulthood, the choice of whether or not to test can be postponed until children are grown up and can decide for themselves.

\section{How is hereditary haemochromatosis treated?}

\section{Phlebotomy}


Haemochromatosis is usually treated with phlebotomy. Each $500 \mathrm{~mL}$ of blood contains $0.25 \mathrm{~g}$ of iron. The concentration of iron above which phlebotomy is indicated is not clear. A meta-analysis has shown that serum ferritin concentrations above $1000 \mu \mathrm{g} / \mathrm{L}$ may cause cirrhosis of the liver.11 A consensus based approach is to start treatment when serum ferritin rises above local reference values (about $300 \mu \mathrm{g} / \mathrm{L}$ and $200 \mu \mathrm{g} / \mathrm{L}$ for men and women, respectively). 1 However, not all patients with raised serum ferritin show further increases.31 Therefore, for patients with moderately raised serum ferritin a "watchful waiting" approach, with phlebotomy only when their serum ferritin increases progressively, might be an alternative to regular phlebotomy.32

The optimum frequency of phlebotomy and quantity of blood taken are unclear, but expert consensus suggests that $500 \mathrm{~mL}$ of blood should be taken each week in the depletion stage, guided most usually by serum ferritin and haemoglobin values.19 The procedure used is similar to that for blood donations. If phlebotomy results in anaemia, or adverse consequences of hypovolaemia, frequency of bleeding or volumes of blood taken can be adjusted.

No evidence is available to help set a target value for serum ferritin. Some authors recommend aiming for 50 $\mu \mathrm{g} / \mathrm{L}$ or even lower.1 However, it might be better to aim for values within the normal range because these might be better tolerated by patients, result less often in anaemia, and prevent an increase in intestinal iron uptake caused by further lowering of hepcidin as a result of intensive blood letting.33 The maintenance stage is reached when serum ferritin drops below the target value. The optimum frequency of phlebotomy will depend on the patient's symptoms and response to treatment, the serum ferritin value at diagnosis, and patient preferences.

An observational study reported that adherence to phlebotomy was greater than $90 \% .34$ The main negative effects were problems with venous access and the time consuming nature of the treatment.35 Observational studies have shown that fibrosis of the liver may be reversed by phlebotomy. The effects on symptoms have not been evaluated extensively, and reviews show that treatment can improve some symptoms, such as fatigue and skin pigmentation, but not others, such as arthralgia.1936 In addition, evidence that treatment improves survival is limited because the low absolute risk of death from cirrhosis or hepatocellular carcinoma makes it difficult to show an effect using observational data.23 A randomised clinical trial to evaluate the effect of phlebotomy would probably be considered unethical and would be complicated because of variable penetrance.

\section{Iron chelation}

Currently, the only routinely available alternative to phlebotomy is iron chelation, which is more costly and has more side effects. In iron chelation with desferrioxamine ferric ions are bound into ferrioxamine complex and eliminated from the body via the urine. Side effects include gastrointestinal symptoms, dizziness, visual and auditory impairments, muscle cramps, tachycardia, and thrombopenia. Experts recommend chelation with desferrioxamine only when phlebotomy is contraindicated-for example, when venous access cannot be obtained and in patients with circulatory problems (such as heart failure or anaemia).

\section{Therapeutic erythrocytapheresis}

Therapeutic erythrocytapheresis is the removal of erythrocytes only rather than whole blood that could become an alternative to phlebotomy. Preliminary results show that erythrocytapheresis leads to a fourfold reduction of phlebotomy sessions. More than twice as much iron can be removed per session and side effects are reduced.37

\section{What can patients do to influence the disease?}

Whether avoiding dietary iron reduces iron storage has not been investigated. Expert consensus opinion is that patients should avoid iron containing food supplements.1 Patients might want to limit alcohol consumption, especially when not yet iron depleted, because alcohol has a toxic effect on the liver and may also suppress hepcidin expression, as summarised in two reviews.138 However, dietary advice that is too strict may reduce quality of life or even reduce adherence. 


\section{How do we monitor patients with haemochromatosis?}

Patients are monitored mainly to guide the timing of treatment and detect liver damage. Serum ferritin is the main parameter used because an observational study found that it correlates with symptoms and the risk of complications. A cross sectional study showed that when serum ferritin is less than $1000 \mu \mathrm{g} / \mathrm{L}$ the risk of serious liver damage is below $1 \% .39$ Serum ferritin levels above $1000 \mu \mathrm{g} / \mathrm{L}$ are, according to international consensus, an indication for liver biopsy because of the risk of cirrhosis. 19 When a liver biopsy shows cirrhosis, periodic screening for hepatocellular carcinoma becomes mandatory. This can be done with echography or magnetic resonance imaging.

\section{Ongoing research}

New chelators, hepcidin agonists, proton pump inhibitors, and calcium antagonists are under evaluation. Clinical trials are needed to assess their clinical value

The predictive value of various combinations of symptoms for the presence of haemochromatosis

The optimal screening approach

Parameters that could help determine the optimum frequency of phlebotomy and the quantity of blood taken at each session, including the optimum target value of serum ferritin

Non-invasive alternatives to liver biopsy as an indicator of liver damage

Greater understanding of how the synthesis of hepcidin is regulated in the liver may provide insight into the reasons for low clinical penetrance and provide markers that could help predict penetrance in C282Y homozygotes

International and national evidence based clinical practice guidelines must be developed and implemented because differences between centres cause anxiety among patients

\section{Additional educational resources}

\section{Resources for healthcare professionals}

European Iron Club (www.euro-iron.org)—European organisation for professionals interested in iron metabolism International Biolron Society (www.bioiron.org)_International organisation for professionals interested in iron metabolism

Lee PL, Beutler E. Regulation of hepcidin and iron-overload disease. Annu Rev Pathol Mech Dis 2009;4:489-515

Weiss G. Genetic mechanisms and modifying factors in hereditary hemochromatosis. Nat Rev Gastroenterol Hepatol 2010;7:50-8.

American Association for the Study of Liver Diseases. Practice guidelines. $\underline{\text { www.aasld.org/practiceguidelines/Pages/PracticeGuidelinesAlpha.aspx }} \underline{\underline{x}}$

European Association for the Study of the Liver. EASL clinical practice guidelines for HFE hemochromatosis. J Hepatol 2010;53:3-22

\section{Resources for patients}


The European Federation of Associations of Patients with Haemochromatosis (www.europeanhaemochromatosis.eu)_Provides links to patient organisations in several countries

American Hemochromatosis Society (www.americanhs.org)—Provides education and support for patients Up-to-Date (www.utdol.com/patients/content/topic.do?topicKey= jo3tricadskc9/\#H25)—Overview about haemochromatosis

Haemochromatosis Society UK (www.haemochromatosis.org.uk/home.html)—Provides help, support, and information for those affected by haemochromatosis

\section{Tips for non-specialists}

Haemochromatosis usually starts with non-specific symptoms and signs. Although evidence is lacking, consider testing for the disease in patients who have had unexplained symptoms for several months

First test for serum ferritin, serum iron, and transferrin, then calculate the transferrin saturation value. If serum ferritin and transferrin saturation are both high, refer the patient to a specialist in haemochromatosis (usually a gastroenterologist)

Repeated phlebotomy is the cornerstone of treatment, although new treatments are under development Population screening is not indicated. Screening of first degree relatives with symptomatic haemochromatosis is indicated

If treated adequately, patients with symptomatic haemochromatosis have a normal life expectancy

\section{Notes}

Cite this as: $B M J$ 2011;342:c7251

\section{Footnotes}

- Contributors: MAvB wrote the first draft of the manuscript and is guarantor. CThBMvD coauthored the manuscript, gave critical feedback, provided details on laboratory testing and H63D mutation, and invited the patient to tell his story. DWS coauthored the manuscript, provided critical comments on the various versions of the manuscript, and drafted the figures and differential diagnosis box.

- Funding: None received.

- Competing interests: All authors have completed the Unified Competing Interest form at www.icmje.org/coi disclosure.pdf (available on request from the corresponding author) and declare: no support from any organisation for the submitted work; no financial relationships with any organisations that might have an interest in the submitted work in the previous three years; no other relationships or activities that could appear to have influenced the submitted work.

- Provenance and peer review: Not commissioned; externally peer reviewed.

- Patient consent obtained.

\section{References}

1. European Association for the Study of the Liver. EASL clinical practice guidelines for HFE hemochromatosis. $J$ Hepatol2010;53:3-22. 
2. Cuijpers M, Raymakers R, MacKenzie A, de Witte T, Swinkels D. Recent advances in the understanding of iron overload in sideroblastic myelodysplastic syndrome. Br J Haematol2010;149:322-3.

3. Lee PL, Beutler E. Regulation of hepcidin and iron-overload disease. Annu Rev Pathol Mech Dis2009;4:489-515.

4. Whitlock E, Garlitz B, Harris E, Beil T, Smith P. Screening for hereditary hemochromatosis: a systematic review for the US Preventive Services Task Force. Ann Intern Med2006;145:209-23.

5. Beutler E, Felitti VJ, Koziol JA, Ho NJ, Gelbart T. Penetrance of 845G $\rightarrow$ A (C282Y) HFE hereditary haemochromatosis mutation in the USA. Lancet2002;359:211-8.

6. Allen KJ, Gurrin LC, Constantine CC, Osborne NJ, Delatycki MB, Nicoll AJ, et al. Iron-overload-related disease in HFE hereditary hemochromatosis. N Engl J Med2008;358:221-30.

7. Wood MJ, Powell LW, Ramm GA. Environmental and genetic modifiers of the progression to fibrosis and cirrhosis in hemochromatosis. Blood2008;111:4456-62.

8. Weiss G. Genetic mechanisms and modifying factors in hereditary hemochromatosis. Nat Rev Gastroenterol Hepatol2010;7:50-8.

9. Swinkels D, Jorna A, Raymakers R. Synopsis of the Dutch multidisciplinary guideline for the diagnosis and treatment of hereditary haemochromatosis. Neth J Med2007;65:452-5.

10. European Association for the Study of the Liver. EASL international consensus conference on haemochromatosis. $J$ Hepatol2000;33:485-504.

11. Ellervik C, Birgens H, Tybjærg-Hansen A, Nordestgaard BG. Hemochromatosis genotypes and risk of 31 disease endpoints: meta-analyses including 66000 cases and 226000 controls. Hepatology2007;46:1071-80.

12. Allen KJ, Bertalli NA, Osborne NJ, Constantine C, Delatycki MB, Nisselle AE, et al. HFE Cys282Tyr homozygotes with serum ferritin concentrations below $1000 \mu \mathrm{g} / \mathrm{L}$ are at low risk of hemochromatosis. Hepatology2010;52:925-33.

13. McLaren GD, McLaren CE, Adams PC, Barton JC, Reboussin DM, Gordeuk VR, et al. Clinical manifestations of hemochromatosis in HFE C282Y homozygotes identified by screening. Can J Gastroenterol2008;22:923-30.

14. Pietrangelo A. The penetrance of hemochromatosis: mice to the rescue. Gastroenterology2007;132:805-8.

15. Fischer R, Harmatz PR. Non-invasive assessment of tissue iron overload. Hematology2009:215-21.

16. Swinkels DW, Janssen MC, Bergmans J, Marx JJ. Hereditary hemochromatosis: genetic complexity and new diagnostic approaches. Clin Chem2006;52:950-68.

17. Kemna EH, Tjalsma H, Willems HL, Swinkels DW. Hepcidin: from discovery to differential diagnosis. Haematologica2008;93:90-7.

18. McDonnell S, Phatak PS, Felitti V, Hover H, McLaren GD. Screening for hemochromatosis in primary care settings. Ann Intern Med1998;129:962-70.

19. Bryant J, Cooper K, Picot J, Clegg A, Roderick P, Rosenberg W, et al. A systematic review of the clinical validity and clinical utility of DNA testing for hereditary haemochromatosis type 1 in at-risk populations. J Med Gen2008;45:513-8.

20. Gurrin LC, Bertalli NA, Dalton GW, Osborne NJ, Constantine CC, McLaren CE, et al. HFE C282Y/H63D compound heterozygotes are at low risk of hemochromatosis-related morbidity. Hepatology2009;50:94-101.

21. El-Serag HB, Inadomi JM, Kowdley KV. Screening for hereditary hemochromatosis in siblings and children of affected patients. A cost-effectiveness analysis. Ann Int Med2000;132:261-9.

22. Asberg A, Hveem K, Thorstensen K, Ellekjter E, Kannelønning K, Fjøsne U, et al. Screening for hemochromatosishigh prevalence and low morbidity in an unselected population of 65238 persons. Scand J Gastroentero/2001;36:110815.

23. Niederau C, Fischer R, Sonnenberg A, Stremmel W, Trampisch HJ, Strohmeyer G, et al. Survival and causes of death in cirrhotic and in noncirrhotic patients with primary hemochromatosis. N Engl J Med 1985;313:1256-62.

24. Elmberg M, Hultcrantz R, Ebrahim F, Olsson S, Lindgren S, Lööf L, et al. Increased mortality risk in patients with phenotypic hereditary hemochromatosis but not in their first-degree relatives. Gastroenterology2009;137:1301-9.

25. Jacobs E, Hendriks J, Marx J, van Deursen C, Kreeftenberg H, de Vries R, et al. Morbidity and mortality in first-degree relatives of $\mathrm{C} 282 \mathrm{Y}$ homozygous probands with clinically detected haemochromatosis compared with the general population: the HEmochromatosis FAmily Study (HEFAS). Neth J Med2007;65:425-33. 
26. Ellervik C, Mandrup-Poulsen T, Nordestgaard BG, Larsen EL, Appleyard M, Frandsen M, et al. Prevalence of hereditary haemochromatosis in late-onset type 1 diabetes mellitus: a retrospective study. Lancet2001;358:1405-9.

27. Niederau C, Fischer R, Pürschel A, Stremmel W, Häussinger D, Strohmeyer G. Long-term survival in patients with hereditary hemochromatosis. Gastroenterology1996;110:1107-19.

28. US Preventive Services Task Force. Screening for hemochromatosis: recommendation statement. Ann Intern Med2006;145:204-8.

29. Walsh A, Dixon JL, Ramm GA, Hewett DG, Lincoln DJ, Anderson GJ, et al. The clinical relevance of compound heterozygosity for the C282Y and H63D substitutions in hemochromatosis. Clin Gastroenterol Hepatol2006;4:1403-10.

30. Jacobs EMG, Hendriks JCM, van Deursen CTBM, Kreeftenberg HG, de Vries RA, Marx JJM, et al. Severity of iron overload of proband determines serum ferritin levels in families with HFE-related hemochromatosis: The HEmochromatosis FAmily Study. J Hepatol2009;50:174-83.

31. Gurrin L, Osborne N, Constantine C, McLaren C, English D, Gertig D, et al. The natural history of serum iron indices for HFE C282Y homozygosity associated with hereditary hemochromatosis. Gastroenterology2008;135:1945-52.

32. Seamark CJ, Hutchinson M, Heath I, McMullin MF. Controversy in primary care: Should asymptomatic haemochromatosis be treated? Treatment can be onerous for patient and doctor. BMJ2000;320:1314-7.

33. Van Dijk BA, Laarakkers CM, Klaver SM, Jacobs EM, van Tits LJH, Janssen MC, et al. Serum hepcidin levels are innately low in HFE-related haemochromatosis but differ between C282Y-homozygotes with elevated and normal ferritin levels. Br J Haemato/2008;142:979-85.

34. Hicken BL, Tucker DC, Barton JC. Patient compliance with phlebotomy therapy for iron overload associated with hemochromatosis. Am J Gastroenterol2003;98:2072-7.

35. McDonnell S, Grindon A, Preston B, Barton J, Edwards C, Adams P. A survey of phlebotomy among persons with hemochromatosis. Transfus Apher Sci1999;39:651-6.

36. Falize L, Guillygomarc'h A, Perrin M, Lainé F, Guyader D, Brissot P, et al. Reversibility of hepatic fibrosis in treated genetic hemochromatosis: a study of 36 cases. Hepatology2006;44:472-7.

37. Rombout-Sestrienkova E, van Noord PA, van Deursen CT, Sybesma BJ, Nillesen-Meertens AE, Koek GH, et al. Therapeutic erythrocytapheresis versus phlebotomy in the initial treatment of hereditary hemochromatosis-a pilot study. Transfus Apher Sci2007;36:261-7.

38. Beutler E. Iron storage disease: Facts, fiction and progress. Blood Cells Mol Dis 2007;39:140-7.

39. Morrison ED, Brandhagen DJ, Phatak PD, Barton JC, Krawitt EL, El-Serag HB, et al. Serum ferritin level predicts advanced hepatic fibrosis among US patients with phenotypic hemochromatosis. Ann Int Med2003;138:627-33. 